\title{
Comparison of Vascular Complications in Patients with Percutaneous Coronary Intervention by Trans-radial and Trans-femoral Approach
}

\author{
ABM Riaz Kawsar ${ }^{1}$, Mir Jamal Uddin², Abdul Momen ${ }^{3}$, Tariq Ahmed Chowdhury ${ }^{4}$, Kajal Kumar Karmoker ${ }^{3}$, \\ Samir Kumar Kundu ${ }^{3}$, Md. Monsurul Hoque ${ }^{3}$, Sharadindu Shekhar Roy ${ }^{5}$, \\ Anup Kumar Howlader ${ }^{1}$, Mohammad Abdul Matin ${ }^{6}$
}

\begin{abstract}
:
Background and Objective: Trans-radial approach of coronary catheterization has been increasingly used as an alternative to transfemoral approach due to less vascular complications, earlier ambulation and improved patient comfort. The aim of the study was to compare procedural and post procedural vascular complications in patients with percutaneous coronary intervention by trans-radial and transfemoral approach.

Methods: This observational comparative study was conducted in the National Institute of Cardiovascular Diseases between June 2015 to May 2016. A total of 180 patients were categorized into two groups according to the approach of the percutaneous coronary intervention (PCI). Group I comprising 90 patients who underwent trans-radial $\mathrm{PCl}$ and group II consists of 90 patients who underwent transfemoral $\mathrm{PCl}$. Patients with an abnormal Allen's test, acute coronary syndrome, history of coronary artery bypass surgery, chronic renal insufficiency or older age (>75 years) were excluded.

Results: Patient demographics were the same in both groups. The mean procedural time in $\min (37.44 \pm 5.13 \mathrm{vs}$ $34.14 \pm 4.42, p=0.004)$ and fluoroscopy time in min
\end{abstract}

$(21.62 \pm 4.11$ vs $17.55 \pm 2.78, p=0.02)$ were more in TR-PCI group but the mean haemostasis time in $\min (7.58 \pm 1.11$ vs $15.59 \pm 3.33, p=0.005$ ) and ambulation time in hour $(0.00 \pm 0.00$ vs $15.59 \pm 3.33, p=<0.001)$ were more in TF-PCI group. Significant arterial spasm following puncture $(6.7 \%$ vs $0 \%, p=0.01)$ were found in trans-radial group but access site bleeding during procedure $(2.2 \%$ vs $8.9 \%$, $\mathrm{p}=0.04$ ) were more in TF-PCI group. After the procedure major hematoma ( $0 \%$ vs $4.4 \%, p=0.04)$, minor hematoma ( $5.7 \%$ vs $14.4 \%, p=0.04)$ and ecchymosis ( $4.4 \%$ vs $13.3 \%)$ were significant in TF-PCI group but vessel occlusion $(5.7 \%$ vs $0 \%, p=0.02)$ were significant in $\mathrm{TR}-\mathrm{PCl}$ group. The mean hospital stays, day $(1.64 \pm 0.42$ vs $2.54 \pm 0.62)$ were more in TF-PCl group.

Conclusion: TR-PCI is safe in respect of procedural and post procedural vascular complications. Trans-radial procedure leads to improved quality of life after the procedure and thus gives much comfort to the patient. It also shortened mean duration of hospital stay. So, trans-radial approach is an attractive alternative to conventional transfemoral approach.

Key Words: Vascular complications, TR-PCI, TF-PCI.

1. Assistant Registrar, Department of Cardiology, National Institute of Cardiovascular Diseases, Dhaka, Bangladesh.

2. Professor, Department of Cardiology, National Institute of Cardiovascular Diseases, Dhaka, Bangladesh.

3. Associate Professor, Department of Cardiology, National Institute of Cardiovascular Diseases, Dhaka, Bangladesh.

4. Assistant Professor, Department of Cardiology, National Institute of Cardiovascular Diseases, Dhaka, Bangladesh.

5. Junior Consultant, Department of Cardiology, National Institute of Cardiovascular Diseases, Dhaka, Bangladesh.

6. Junior Consultant, Cardiology, Upazilla Health Complex, Parshuram, Feni, Bangladesh.

Address of Correspondence: Dr. A.B.M. Riaz Kawsar, Department of Cardiology, National Institute of Cardiovascular Diseases, Dhaka, Bangladesh. Email: riazkawsar75@gmail.com 


\section{Introduction:}

Coronary artery disease (CAD) is a major cause of mortality globally and this health problem is reaching pandemic in both developed, as well as in developing countries ${ }^{1}$. Percutaneous coronary intervention $(\mathrm{PCl})$ is the standard treatment for ischemic heart disease and the use of $\mathrm{PCl}$ in appropriate patients reduces morbidity and mortality across the spectrum of risk $^{2}$. Considerable evidence suggests that post-PCl bleeding is associated with an adverse prognosis ${ }^{3}$. Clinical trials evaluating new pharmacological strategies have focused on reducing this risk ${ }^{4}$; however, absolute reductions in bleeding risk have been modest across most studies.

Coronary interventions have been traditionally performed using the femoral approach for arterial access since its inception by Gruntzig ${ }^{5}$ in 1977 to till date due to the fact that its size makes arterial cannulation and catheter manipulation easy. Despite these advantages, femoral access has several limitations. The femoral artery is relatively deep, especially in obese patients, and its proximity to the femoral vein and nerve is a potential source of iatrogenic injury. For this reason, transfemoral $\mathrm{PCl}$ is associated with bleeding complication rates of up to $10 \%$ in the elective setting ${ }^{6}$. Especially under conditions of aggressive anticoagulation and antiplatelet treatment, vascular bleeding complications at the femoral puncture site can result in increased morbidity and duration of hospitalization ${ }^{7}$. Trans-radial approach represents another way to reduce vascular \& bleeding complications that make it an attractive alternative to brachial or femoral approaches ${ }^{8}$.

The radial artery is easily compressible; thus, bleeding is controllable and haemorrhagic complications are significantly reduced and improved clinical outcomes compared with trans-femoral approach in both young and elderly patients ${ }^{9}$.

The trans-radial $\mathrm{PCI}$ is associated with a lower risk of access site bleeding and hematoma, early patient ambulation, shorter length of hospital stays, and lower hospital costs. Moreover, no major veins or nerves are located near the artery, minimizing risk of injury to these structures. Finally, post procedure bed rest is not required, permitting immediate ambulation, more comfort and early discharge which improve quality of life of patients and reduced hospitalization cost ${ }^{10}$.

The trans-radial $\mathrm{PCl}$ may be routinely attempted, with some exceptions and is to be preferred in those patients at high risk of local vascular complications (such as the elderly, the obese, patients with aorta iliac diseases or those receiving anti-thrombotic and anti-platelet drugs). To date, many studies have confirmed the findings of the early pioneers of this technique. Today, 10 years after the first trans-radial $\mathrm{PCI}$, it has found its place among the more conventional catheterization routes. The technique has spread all over the world and its popularity is increasing steadily. Therefore, the rationale for the transradial $\mathrm{PCl}$ is the intention to reduce access site bleeding complications, earlier ambulation, and improved patient comfort ${ }^{11}$.

\section{Methods:}

A total of 180 patients were studied in this comparative study in the Department of Cardiology, National Institute of Cardiovascular Diseases (NICVD), Dhaka from June 2015 to May 2016who underwent elective PCl. The patients were divided into two groups according to the approach of the $\mathrm{PCl}$. The group-I consisted of 90 patients who underwent trans-radial approach and the group- II consisted of 90 patients who underwent trans-femoral approach. Absence of radial artery pulse, Absence of functional collaterals between the radial and the ulnar artery - judged by Modified Allen's Test, Patient with Acute Coronary Syndrome (ACS), Prior coronary artery bypass surgery $(C A B G)$, peripheral vascular disease (e.g. Raynaud's phenomenon.), severe co morbidity (CKD, CVD, COPD) were excluded from the trans-radial $\mathrm{PCl}$ group.

Baseline clinical characteristics such as age, sex, occupation and risk factors including smoking, hypertension, diabetes mellitus and dyslipidemia were noted. Baseline investigations like RBS, serum creatinine, serum lipid profile, coagulation profile and screening blood tests for $\mathrm{PCl}$ were carried out for each of the patients. Procedural and post procedural vascular complications were compared in both groups

Statistical analysis was performed by using SPSS (Statistical Package for Social Science) statistical software (Version 19, SPSS Inc., Chicago, Illinos, USA). Data were expressed in percentage, frequencies and means and standard deviation. Continuous variables were compared through the Student's t-test and for the categorical variables the chi-square test was done. $\mathrm{P}$ value of less than 0.05 was considered as significant.

\section{Results:}

The mean age was found 50.18 $\pm 9.35 y e a r s$ in Group I and $49.94 \pm 8.17$ years in Group II. The mean age difference was insignificant $(p=0.86)$ between two groups. Male patients were predominant in both groups. The Study compares the common risk factors for coronary artery 
diseases between two groups. Smoking was found 60 $(66.7 \%)$ in the group I and $57(63.3 \%)$ patients in the group II). Hypertension was found 55 (66.1\%) and 56 $(62.2 \%)$ in the group I and group II respectively. Diabetes mellitus was found $27(30 \%)$ and $30(33.3 \%)$ in the group I and group II respectively. Dyslipidemia was found 62 $(68.9 \%)$ in the group I and $58(64.4 \%)$ in the group II. Family history of CAD had found 28 (31.1\%) and 25 $(27.8 \%)$ in group I and group II respectively. Mean pulse rate was found $78.3 \pm 5.6 / \mathrm{min}$ in group I and $80.6 \pm 7.8$ / min in group II. The mean systolic blood pressure was $126.6 \pm 16.6 \mathrm{mmHg}$ in group I and $129.3 \pm 16.6 \mathrm{mmHg}$ in group II. The mean diastolic blood pressure was $79.0 \pm 8.8 \mathrm{mmHg}$ in group I and $79.5 \pm 9.2 \mathrm{mmHg}$ in group II. All baseline characteristics were statistically insignificant in both groups.

Mean bleeding time was $3.42 \pm 0.33 \mathrm{~min}$ in group I and $3.56 \pm 0.30 \mathrm{~min}$ in group II. The mean of clotting time was $6.48 \pm 0.6 \mathrm{~min}$ and $6.78 \pm 0.5 \mathrm{~min}$ in group I and group II respectively and both were statistically insignificant difference.

The patients with chronic stable angina were 41 (45.6\%) and $38(42.2 \%)$, NSTEMI were $12(13.3 \%)$ and $10(11.1 \%)$ and STEMI were $37(41.1 \%)$ and $42(46.7 \%)$ in the group I and group II respectively. The differences between two groups were statistically identical $(p>0.05)$ on the basis of clinical diagnosis (Fig.-1).

The mean procedural time was $37.44 \pm 5.13$ min in group I and $34.14 \pm 4.52$ min in group II with statistically significant differences $(p=0.004)$. The mean fluoroscopy time was $21.62 \pm 4.11 \mathrm{~min}$ and $17.55 \pm 2.78 \mathrm{~min}$ in the group I and group II respectively with the statistically significant differences $(p=0.02)$. The mean haemostasis time was $7.58 \pm 1.11 \mathrm{~min}$ and $15.59 \pm 3.33 \mathrm{~min}$ in group I and group II respectively with the statistically significant differences $(p=0.005)$.

The ambulation time was $0.00 \pm 0.00$ hour in group I and $15.84 \pm 4.89$ hour in group II with the statistically significant differences $(p=<0.001)$ (Table-I).

Among the total procedural complications, the number of the patients noticed arterial spasm following puncture was $6(6.7 \%)$ in the group I and none in group II with the statistically significant difference $(p=0.01)$. Considering access site bleeding $2(2.2 \%)$ and $8(8.9 \%)$ study subjects experienced that in the group I and group II respectively and the difference was statistically significant $(p=0.04)$. The number of catheter non-engagement was $3(3.3 \%)$ and none was observed in group II respectively with the statistically insignificant differences $(p=0.08)$ (Table-II).

In the group I, $0(0.0 \%)$ and $4(4.4 \%)$ in the group II had major hematoma with statistically significant differences $(p=0.04)$. There was $5(5.7 \%)$ and $13(14.4 \%)$ minor hematoma in group I and group II with statistically significant differences $(p=0.04)$. There was also ecchymosis in group I subjects 4 (4.4\%) whereas 12 $(13.3 \%)$ patients in group II with statistically significant differences $(p=0.03)$. The vessel occlusion was $5(5.7 \%)$ in group I and none in group II with statistically significant differences $(p=0.02)$.

Artery-venous fistula and limb ischemia were not found in both groups (Table-III). The mean hospital stay for trans-radial approach was $1.64 \pm 0.42$ days while in transfemoral approach it was $2.54 \pm 0.62$ days with the statistically significant differences $(p=0.01)$. (Table-IV).

Table I

Comparison of procedural characteristics of the study population $(n=180)$.

\begin{tabular}{lccc}
\hline Procedural Characteristics & Group I $(\mathrm{n}=90)$ & Group II $(\mathrm{n}=90)$ & pvalue \\
\hline & Mean \pm SD & Mean \pm SD & \\
Procedural time (min) & $37.44 \pm 5.13$ & $34.14 \pm 4.52$ & $0.004^{\mathrm{s}}$ \\
Fluoroscopy time (min) & $21.62 \pm 4.11$ & $17.55 \pm 2.78$ & $0.02^{\mathrm{s}}$ \\
Haemostasis time (min) & $7.58 \pm 1.11$ & $15.59 \pm 3.33$ & $0.005^{\mathrm{s}}$ \\
Ambulation time (hr) & $0.00 \pm 0.00$ & $15.84 \pm 4.89$ & $<0.001^{\mathrm{s}}$ \\
\hline
\end{tabular}

Table-II

Comparison of procedural complications between two groups $(n=180)$.

\begin{tabular}{lcccccc}
\hline Procedural complications & \multicolumn{2}{c}{ Group I $(\mathrm{n}=90)$} & & \multicolumn{2}{c}{ Group II $(\mathrm{n}=90)$} & \multicolumn{2}{c}{$\mathrm{p}$ value } \\
\cline { 2 - 3 } & Number & $\%$ & & Number & $\%$ & \\
\hline Arterial spasm following puncture & 6 & 6.7 & 0 & 0.0 & $0.01^{\mathrm{s}}$ \\
Access site bleeding & 2 & 2.2 & 8 & $8.9^{\text {c }}$ & $0.04^{\mathrm{s}}$ \\
Catheter non-engagement & 3 & 3.3 & 0 & 0.0 & $0.08^{\text {ns }}$ \\
\hline
\end{tabular}


Table-III

Comparison of post procedural complications between two groups $(n=180)$.

\begin{tabular}{|c|c|c|c|c|c|}
\hline \multirow[t]{2}{*}{ Post- procedural complications } & \multicolumn{2}{|c|}{ Group I $(n=90)$} & \multicolumn{2}{|c|}{ Group II $(\mathrm{n}=90)$} & \multirow[t]{2}{*}{$p$ value } \\
\hline & Number & $\%$ & Number & $\%$ & \\
\hline Major hematoma & 0 & 0.0 & 4 & 4.4 & $0.04^{\mathrm{s}}$ \\
\hline Minor hematoma & 5 & 5.7 & 13 & $14.4^{\prime}$ & $0.04^{\mathrm{s}}$ \\
\hline Ecchymosis & 4 & 4.4 & 12 & 13.3 & $0.03^{\mathrm{s}}$ \\
\hline Vessel occlusion & 5 & 5.7 & 0 & 0.0 & $0.02^{\mathrm{s}}$ \\
\hline Artery-venous fistula & 0 & 0.0 & 0 & 0.0 & \\
\hline Limb ischemia & 0 & 0.0 & 0 & 0.0 & \\
\hline
\end{tabular}

Table-IV

Distribution of the study patients by duration of hospital stay after procedure $(n=180)$.

\begin{tabular}{lcccccc}
\hline Duration of hospital stay & \multicolumn{2}{c}{ Group I $(\mathrm{n}=90)$} & & \multicolumn{2}{c}{ Group II $(\mathrm{n}=90)$} & p value \\
\cline { 2 - 3 } after procedure (days) & Number & $\%$ & & Number & $\%$ & \\
\hline$<2$ & 50 & 55.6 & & 0 & 0 \\
$2-3$ & 30 & 33.3 & & 60 & 66.7 \\
$>3$ & 10 & 11.1 & & 30 & 33.3 & \\
Mean \pm SD & \multicolumn{2}{c}{$1.64 \pm 0.42$} & & $2.54 \pm 0.62$ & $0.01^{\text {s }}$ \\
\hline
\end{tabular}

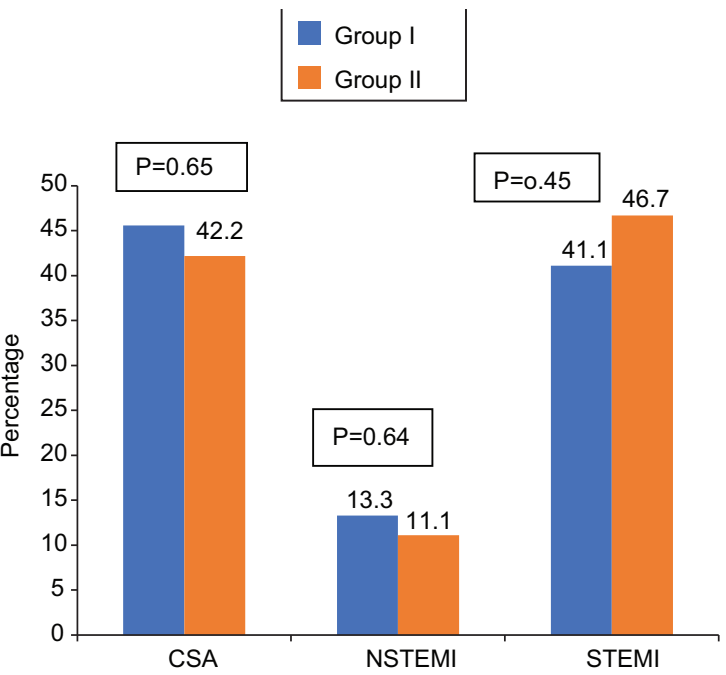

Fig.-1: Clinical diagnosis of the study population.

\section{Discussion:}

This observational study was conducted in the department of cardiology of National Institute of Cardiovascular Diseases (NICVD), Dhaka during the

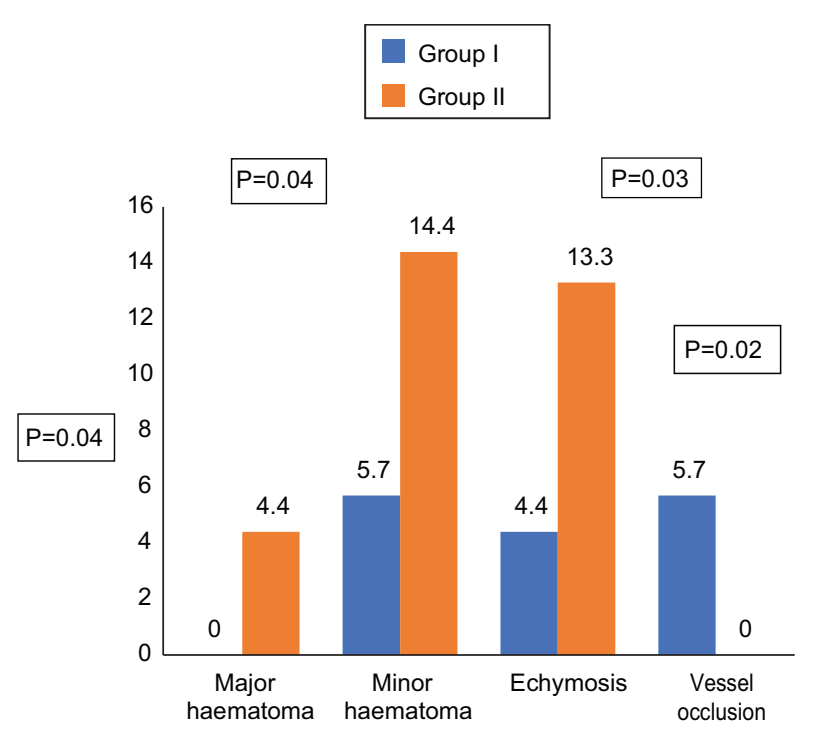

Fig.-2: Post-procedural complications between two groups in percentage.

period of June 2015 to May 2016 to evaluate vascular complications of trans-radial percutaneous coronary intervention compared to the transfemoral percutaneous coronary intervention in CAD patients. A total of 180 
patients with coronary artery disease (CAD) who were admitted for elective percutaneous coronary intervention (PCI), were studied. The patients were divided into two groups according to the approach of the percutaneous coronary intervention $(\mathrm{PCl})$. In the group I patients underwent trans-radial percutaneous intervention and, in the group II, patients underwent transfemoral percutaneous coronary intervention. Each group was comprised of 90patients.

In our study, the mean age, sex and common risk factors for coronary artery disease were not significantly different between two groups. The clinical parameters like Pulse and BP and bio-chemical parameters like RBS, Creatinine, Lipid profile were observed almost identical in both groups of patients. Regarding coagulation profile and clinical diagnosis no significant difference were found between two groups.

We found that, the mean procedural time was more in trans-radial group (Group-I) than in trans-femoral group (Group-II) which was statistically significant. Brueck M. et al $(2009)^{12}$ described in their study of more mean procedural time in trans-radial $\mathrm{PCl}$ group than in transfemoral PCl group. We also found that, Regarding the mean fluoroscopy time was more in trans-radial group (Group-I) than in trans-femoral group (Group-II) with statistically significant value. It resembling a study done by Ibebuogu UN et al (2012) ${ }^{13}$ where total fluoroscopy time was longer in the trans-radial access group compared to the transfemoral access group.

In terms of the haemostasis, the mean time was less in trans-radial group (Group I) than the trans-femoral group (Group II) with statistically significant differences. The result is very much consistent with the mean haemostasis time found by Patwary et al (2009) ${ }^{14}$ in their study.

Among the procedural complications, arterial spasm following puncture was found only in trans-radial $\mathrm{PCl}$ group with the statistically significant differences. Considering access site bleeding, it was less in transradial group than in trans femoral group which was statistically significant. There were no vascular complications in the trans-radial access group compared to the trans-femoral access group observed by Ibebuogu UN et al (2012) ${ }^{13}$ in their study. Dehghani $P$ et al (2009) $)^{15}$ showed in their study, access site bleeding, access site hematoma and radial artery spasm which were the predictors of failed trans-radial $\mathrm{PCl}$. We also found a little number of cases who were shifted to trans-femoral approach due to failed catheter engagement through trans- radial approach.
In our study, post procedural complications were more in trans-femoral PCl group (Group-II) than in trans-radial $\mathrm{PCl}$ group (Group-I) and the difference was statistically significant. Among them no major hematoma was found in trans-radial $\mathrm{PCl}$ group. Minor hematoma was also less in trans-radial group (Group-I) than in trans-femoral group (group-II). The difference was statistically significant. Ecchymosis was less in trans-radial group (Group-I) than in trans-femoral group (Group-II) with statistically significant difference. Finally, the vessels occlusion was found only in trans-radial $\mathrm{PCl}$ group (Group-I). Following transfemoral PCl patients would have to confine in the bed for at least 6 hours when they can't move the leg where as in case of trans-radial $\mathrm{PCl}$ patients can even walk just after the procedure. For first couple of hours this group patient was advised to raise and not to move their operated hand. For this reason, urinary retention and low back pain is common in transfemoral $\mathrm{PCl}$. There was no artery venous fistula, pseudo aneurysm, limb ischemia, and nerve injury's observed. The mean hospital staying was more in transfemoral PCI group with statistically significant differences than in trans-radial $\mathrm{PCl}$ group. It resembles with the mean hospital stay observed by Triantafyllou K et al $(2010)^{14}$.

\section{Conclusion:}

This study was conducted to evaluate the vascular complications of trans-radial percutaneous coronary intervention compared to the transfemoral percutaneous coronary intervention in CAD patients. The present study concluded that TR-PCl is safe in respect of procedural and post procedural vascular complications. More importantly, trans-radial procedure leads to improved quality of life after the procedure and thus gives much comfort to the patient.

\section{Study limitations:}

The study was done in a single center. The sampling method was non-randomized. Hemostasis was achieved by using manual pressure in most of the patients and the study and follow up period was short.

\section{Recommendations:}

The study recommends that vascular complications of trans-radial $\mathrm{PCl}$ was lower than the transfemoral $\mathrm{PCl}$ except in two aspects, arterial spasm following puncture and occlusion of radial artery was more than that of transfemoral $\mathrm{PCl}$. Apart from these two aspects transradial $\mathrm{PCl}$ is safer as well as more convenient. However, the result of this study in context of Bangladesh needs further confirmation in a randomized large scale multicenter prospective cohort study. 


\section{References:}

1. Chaturvedi V, Bhargava B. Health Care delivery for coronary heart disease in India-where are we headed. American heart hospital journal2007; 5: 32-37.

2. Patel TMR, Dehmer GJ, Hirshfeld JW et al. ACCF/ SCAI/STS/AATS/AHA/ASNC 2009 appropriateness criteria for coronary revascularization: a report by the American College of Cardiology Foundation Appropriateness Criteria Task Force, Society for Cardiovascular Angiography and Interventions, Society of Thoracic Surgeons, American Association for Thoracic Surgery American Heart Association, and the American Society of Nuclear Cardiology, Journal of American College of Cardiology2009; 53: $530-553$.

3. Rao SV, Eikelboom JA, Granger CB et al. Bleeding and blood transfusion issues in patients with nonST-segment elevation acute coronary syndromes. European Heart Journal2007; 28: 1193-1204.

4. Montalescot G, White HD, Gallo R et al. Enoxaparin versus unfractionated heparin in elective percutaneous coronary intervention. New England Journal of Medicine2006; 355: 1006 -1017.

5. Gruntzig A. Transluminal dilatation of coronary artery stenosis. Lancet 1978;1: 263.

6. Berry C, Kelly J, Cobbe SM, Eteiba H. Comparison of femoral bleeding complications after coronary angiography versus percutaneous coronary intervention. Journal of American College of Cardiology2004; 94: 361- 363.

7. Cantor WJ, Mahaffey KW, Huang Z et al. Bleeding complications in patients with acute coronary syndrome undergoing early invasive management can be reduced with radial access, smaller sheath sizes, and timely sheath removal. Catheterization and Cardiovascular Intervention 2007; 69:73- 83.

8. Christopher J, Cooper MD, Reda A et al. Effect of trans-radial access on quality of life and cost of cardiac catheterization: A random comparison. American Heart Journal1999; 138: 430-436.

9. Jaffe $\mathrm{R}$, Hong $\mathrm{T}$, Sharieff $\mathrm{W}$ et al. Comparison of radial versus femoral approach for percutaneous coronary interventions in octogenarians. Catheter and Cardiovascular Intervention 2007; 69: 815-820.

10. Agostoni P, Biondi-Zoccai GG, Benedictis ML et al. Radial versus femoral approach for percutaneous coronary diagnostic and interventional procedures Systematic overview and meta-analysis of randomized trials Journal of American College of Cardiology2004; 44: 349- 356.

11. Kiemeneij F, Laarman GJ, Odekerken D et al.Randomized comparison of percutaneous transluminal coronary angioplasty by the radial, brachial and femoral approaches. Journal of American college of Cardiology1997; 29: 1269 1275.

12. Brueck $M$, Dirk B, Wilfried $K$ et al. A Randomized Comparison of Trans-radial Versus Transfemoral Approach for Coronary Angiography and Angioplasty: Mini-Focus Issue: Trans-radial Approach Clinical Research. Cardiovascular Interventions2009; 2 :1047-1054.

13. Ibebuogu UN, Cercek B, Makkar R et al. Comparison Between Trans-radial and Transfemoral Percutaneous Coronary Intervention in Acute ST-Elevation Myocardial Infarction. American Journal of Cardiology2012;110: 1262-1265.

14. Triantafyllou K. Radial Approach to Percutaneous Coronary Intervention, Hospital Chronicles 2010, Athens Cardiology Update2010; 1:128-36. 